Jurnal Homepage: http:/journal2.um.ac.id/index.php/jaa (p-ISSN: 2087-9695; e-ISSN: 2580-1015)

\title{
Kepemilikan keluarga dan carbon emission disclosure pada perusahaan pertambangan yang terdaftar di bursa efek indonesia
}

\author{
Rahman Anshari*1, Isnalita ${ }^{2}$ \\ ${ }^{1}$ Program Studi Manajemen, Fakultas Ekonomi Hukum Politik dan Psikologi, Universitas Muhammadiyah \\ Kalimantan Timur, Jl. Ir. H. Djuanda No. 15 Samarinda, Indonesia \\ ${ }^{2}$ Departemen Akuntansi, Fakultas Ekonomi dan Bisnis, Universitas Airlangga, Jl. Airlangga No.46 Surabaya, Indonesia
}

Diterima: Juni 2019

Direvisi: Juli 2019,

September 2019

Disetujui: Desember 2019

Koresponding:

Rahman Anshari

idn.anshari@gmail.com

DOI:

http://dx.doi.org/10.17977/ um004v7i12020p11

\begin{abstract}
This research aims to empirically examine the relationship between family ownership and Carbon Emission Disclosure (CED) on mining companies. The sample are all of the mining companies listed on the Indonesia Stock Exchange from 2016 to 2017. Saturated sampling technique is used on this research, so that 46 companies' are chosen through that technique. Dependent variable used in this research is carbon emission's disclosure, measured by using carbon disclosure project (CDP) index. Firm's size and firm's age are used as the control variable. The data was analyzed by using multiple regression analysis. The result shows that family ownership has a negative and significant effect on carbon emission disclosure. The result also shows that mining family companies tend to not disclose information on carbon emission they produced comprehensively. Based on the result of this research, government should create policies about carbon emission disclosure to increase carbon emission disclosure.
\end{abstract}

Keywords: Carbon Emissions Disclosure; Family Ownership; Mining Companies

\begin{abstract}
Abstrak
Penelitian ini bertujuan untuk menguji secara empiris pengaruh kepemilikan keluarga terhadap Carbon Emission Disclosure (CED) di perusahaan pertambangan dengan menggunakan sampel perusahaan pertambangan yang dimiliki oleh keluarga yang terdaftar di Bursa Efek Indonesia pada tahun 2016-2017. Sampel diambil dengan menggunakan teknik sampling jenuh sehingga diperoleh 46 sampel penelitian. Variabel independen penelitian ini adalah kepemilikan keluarga yang diukur menggunakan prosentase kepemilikan saham. Variabel dependen penelitian ini adalah carbon emission disclosure yang diukur menggunakan indeks pengungkapan carbon disclosure project (CDP). Penelitian ini menggunakan dua variabel kontrol yaitu ukuran perusahaan dan usia perusahaan. Penelitian ini menggunakan analisis regresi berganda. Hasil penelitian menunjukkan bahwa kepemilikan keluarga berpengaruh negatif dan signifikan terhadap carbon emission disclosure. Implikasi dari penelitian ini adalah perusahaan pertambangan keluarga cenderung tidak mengungkapkan informasi mengenai emisi karbon yang dihasilkan perusahaan dengan komprehensif, sehingga diperlukan kebijakan-kebijakan pemerintah yang meningkatkan kepatuhan pengungkapan.

Kata Kunci: Pengungkapan Emisi Karbon; Kepemilikan Keluarga; Perusahaan Pertambangan
\end{abstract}

\section{PENDAHULUAN}

Salah satu potensi sumber daya alam yang dimiliki oleh Indonesia adalah bidang pertambangan komoditas mineral antara lain batubara, minyak, gas bumi, emas, timah, tembaga dan nikel. Berdasarkan data Badan Pusat Statistik (BPS) 2018, jumlah perusahaan besar yang bergerak di bidang pertambangan migas sebanyak 123 perusahaan, gheotermal sebanyak 5 perusahaan, pengilangan sebanyak 17 perusahaan, non-migas (batubara, timah, bauksit, bijih nikel, emas dan perak, konsentrat tembaga, serta aspal) sebanyak 922 perusahaan. Banyaknya perusahaan pertambangan di Indonesia berdampak pada besarnya potensi pencamaran yang terjadi akibat operasional perusahaaan. Choi dkk. (2013) menyatakan pemanasan global telah menjadi masalah politik dan bisnis yang semakin penting bagi sebagian besar negara. Seruan kuat datang dari para pemerhati lingkungan, bisnis dan politik untuk menanggapi berbagai tantangan - tantangan yang diakibatkan oleh ancaman pemanasan global. Salah satu tantangan adalah perlunya suatu entitas untuk memahami dan mengkomunikasikan kontribusinya terhadap pemanasan global yang dihasilkan dari emisi karbon (Choi dkk., 2013). 
Pada tahun 2004, Indonesia mengeluarkan Undang-Undang No. 17 tahun 2004 tentang Pengesahan Kyoto Protocol to the United Nations Framework Convention on Climate Change (Protokol Kyoto atas Konvensi Kerangka Kerja Perserikatan Bangsa-Bangsa Tentang Perubahan Iklim). Pokok bahasan dari Protocol Kyoto adalah mewajibkan seluruh anggota Anex 1 untuk mengurangi efek Gas Rumah Kaca (GRK). Emisi GRK menurut Annex A Protokol Kyoto meliputi Carbon Dioxide (CO2), Methane (CH4), Nitrous Oxide (N2O), Hydrofluorocarbon (HFC), Perfluorocarbon (PFC), dan Sulfurhexafluoride (SF6). Dengan dikeluarkannya undang-undang tersebut, Indonesia ikut berkomitmen untuk bersama-sama menjaga dan melindungi kehidupan manusia dan ekosistem di bumi dari perubahan iklim dan pemanasan global. Implikasi dari Protocol kyoto adalah munculnya carbon accounting; yaitu perusahaan diharuskan untuk melakukan pengakuan, pengukuran, pencatatan, penyajian, dan pengungkapan emisi karbon (Irwhantoko dan Basuki, 2016).

Penelitian pengungkapan emisi karbon yang dilakukan oleh Choi dkk. (2013) menemukan bahwa perusahaan yang lebih besar mengungkapkan emisi karbon yang lebih komprehensif dibanding perusahan yang lebih kecil. Selain itu, perundang-undangan negara juga dapat mendorong perusahaan untuk mengungkapan emisi karbon yang lebih komprhensif secara sukarela. Penelitian Gonzalez-Gonzalez dan Zamora-Ramírez (2016) yang menganalisis faktor yang mempunyai kontribusi terhadap keputusan perusahaan mengungkapkan informasi emisi karbon menemukan bahwa ukuran perusahaan, risiko keuangan serta konsentrasi kepemilikan mempunyai pengaruh yang signifikan terhadap kontribusi keputusan pengungkapan emisi karbon. Ben-Amar dkk. (2017) yang menguji pengaruh direksi perempuan terhadap pengungkapan emisi karbon menemukan bahwa terjadi peningkatan pengungkapan emisi karbon ketika persentase perempuan lebih tinggi pada dewan perusahaan. Penelitian lain dilakukan oleh Kılıç dan Kuzey (2019) yang menganalisis pengaruh direksi independen dan diversitas kewarganegaraan direksi serta komite keberlanjutan terhadap pengungkapan emisi karbon. Hasil penelitian menemukan bahwa diversitas kewarganegaraan direksi dan komite keberlanjutan berpengaruh positif dan signifikan terhadap pengungkapan emisi karbon. Penelitian lain dilakukan oleh Nasih dkk. (2019) yang menganalisis pengaruh ukuran perusahaan dan strukutur tata kelola perusahaan terhadap pengungkapan emisi karbon. Hasil penelitian tersebut menemukan bahwa perusahaan besar dan yang memiliki ukuran dewan yang besar mengungkapkan informasi emisi karbon yang lebih komprehensif selain prorporsi komisaris dan direksi independen yang lebih banyak.

Berdasarkan penelitian sebelumnya, masih belum banyak yang menguji pengaruh kepemilikan perusahaan terhadap pengungkapan emisi karbon. Penelitian Gonzalez-Gonzalez dan ZamoraRamírez (2016) menemukan bahwa kosentrasi kepemilikan pada perusahaan mempunyai peran terhadap keputusan pengungkapan emisi karbon. Namun, penelitian tersebut belum mengidentifikasi jenis kepemilikan perusahaan, sehingga masih ada celah penelitian pada fokus tersebut. Oh dkk. (2011) berargumen bahwa faktor kepemilikan perusahaan menjadi penting untuk ditelaah lebih jauh karena struktur kepemilikan perusahaan yang berbeda mempunyai motivasi yang berbeda pula terhadap pengungkapan informasi non keuangan.

Survei PricewaterhouseCooper atau PWC (2014) menunjukkan bahwa 95\% perusahaan yang ada di Indonesia adalah perusahaan keluarga. Hal tersebut mengindikasikan bahwa, mayoritas perusahaan di Indonesia memiliki struktur kepemilikan yang bersifat terkonsentrasi. Perusahaan keluarga adalah perusahaan yang unik karena mereka cenderung akan berusaha menjaga perusahaan untuk dapat diwariskan ke generasi selanjutnya (Oh dkk., 2011). Pengungkapan menjadi salah satu cara perusahaan untuk berkomunikasi dan menunjukkan tanggung jawabnya kepada pemangku kepentingan. Salah satu pemangku kepentingan adalah masyarakat sehingga pengungkapan yang komprehensif bisa memunculkan citra baik perusahaan di masyarakat dengan menunjukkan bahwa perusahaan peduli terhadap isu emisi karbon atas aktivitas operasional pertambangan. Sebaliknya, ketika perusahaan tidak melakukan pengungkapan dengan komprehensif, maka hal ini menunjukkan ketidakpedulian perusahaan terhadap tuntutan akan keterbukaan informasi dari berbagai pemangku kepentingan perusahaan.

Berdasarkan pemaparan sebelumnya, penelitian ini bertujuan untuk menguji secara empiris pengaruh kepemilikan keluarga terhadap pengungkapan emisi karbon pada perusahaan pertambangan yang terdaftar di Bursa Efek Indonesia (BEI) yang dikendalikan oleh keluarga. Kebaharuan penelitian ini yaitu adanya variabel struktur kepemillikan berupa kepemilikan keluarga yang digunakan sebagai variabel indepenenden. Variabel tersebut dipilih karena banyaknya perusahaan di Indonesia yang dikendalikan oleh keluarga sehingga faktor tersebut diduga dapat memengaruhi motivasi perusahaan pertambangan untuk mengungkapkan emisi karbon dengan komprehensif.

Penelitian ini menggunakan teori socioemotional wealth sebagai dasar untuk memahami masalah penelitian. Teori socioemotional wealth menjelaskan bahwa keluarga memiliki aspek non keuangan 
dari perusahaan guna memenuhi kebutuhan afektif keluarga seperti identitas, kemampuan keluarga dalam memengaruhi perusahaan, keinginan keluarga untuk menggunakan wewenang, kelangsungan kepemimpinan keluarga dan wewenang dalam menunjuk anggota keluarga yang dipercaya untuk menduduki posisi penting (Gómez-Mejía dkk., 2007). Kellermanns dkk. (2012) menyatakan bahwa kerangka acuan sosioemotional wealth merupakan pendorong perilaku perusahaan keluarga untuk mementingkan diri sendiri dan menempatkan kebutuhan keluarga di atas pemangku kepentingan lain. Berdasarkan sudut pandang teori socioemotional wealth, pengungkapan informasi sukarela pada perusahaan keluarga akan berada pada tingkat yang rendah karena perusahaan keluarga memiliki tingkat asimetri informasi yang rendah, tuntutan dari pemangku kepentingan yang sedikit dan adanya kekhawatiran akan mengganggu keuangan perusahaan sehingga perusahaan keluarga menjadi kurang responsif terhadap permintaan pengungkapan dari para pemangku kepentingan dan lebih mengutamakan kepentingan keluarga di perusahaan (Gómez-Mejía dkk., 2007; Kim dkk., 2017; Muttakin dan Khan, 2014).

Di Indonesia, pengungkapan emisi karbon masih bersifat sukarela. Pemerintah belum membuat regulasi yang mewajibkan pengungkapan tersebut, terutama bagi perusahaan publik. Walaupun demikian, perusahaan pertambangan harus menyadari bahwa emisi karbon yang dihasilkan dari aktivitas pertambangan merupakan salah satu penyumbang efek rumah kaca. Industri pertambangan, seperti minyak bumi, batu bara, dan gas alam, menggunakan 70\% energi fosil dari total energi yang dikonsumsi (Nasih dkk., 2019) sehingga industri pertambangan adalah penyumbang terbesar emisi karbon di negara-negara berkembang, termasuk Indonesia (Nasih dkk., 2019). Berdasarkan sudut pandang teori socioemotional wealth, walaupun perusahaan pertambangan menyumbang banyak emisi karbon dari aktivitas operasionalnya, perusahaan keluarga akan cenderung berperilaku mengabaikan pemangku kepentingan eksternal perusahan oleh karena kepentingan pihak internal untuk melakukan pengungkapan yang komprehensif menjadi relatif lemah. Hal ini karena mereka terlibat aktif di perusahaan dan mudah memperoleh informasi perusahaan untuk pengambilan keputusan.

\section{Kepemilikan Keluarga dan Carbon Emission Disclosure}

Muttakin dan Khan (2014) menyatakan bahwa perusahaan keluarga memiliki motivasi yang rendah terhadap pengungkapan sukarela yang melebihi batas wajib disyaratkan. Namun, perusahaan keluarga lebih tertarik pada profitabilitas dan kinerja keuangan daripada masalah sosial dan lingkungan (Déniz dan Suárez, 2005). Ho dan Wong (2001) menjelaskan bahwa pada perusahaan keluarga, keterlibatan anggota keluarga pada kegiatan sehari-hari perusahaan mengakibatkan mekanisme kontrol seperti pengungkapan informasi sukarela menjadi tidak diperlukan. Ketika keluarga merupakan pemegang saham utama dan anggota keluarga berada pada jajaran dewan direksi maka mereka mempunyai akses langsung terhadap informasi keuangan dan non keuangan sehingga membutuhkan sedikit pengungkapan (Chau dan Gray, 2010). Penelitian Gonzalez-Gonzalez dan Zamora-Ramírez (2016) menunjukkan bahwa perusahaan dengan jenis kepemilikan yang terkonsentrasi berpengaruh negatif terhadap pengungkapan emisi karbon.

Sesuai dengan teori socioemotional wealth, perusahaan yang dimiliki oleh keluarga cenderung bersifat oportunis. Praktik bisnis pada perusahaan keluarga berbeda dengan perusahaan jenis lain. Hal tersebut juga berdampak pada pola perilaku perusahaan keluarga yang berbeda dengan jenis perusahaan lain karena perusahaan keluarga akan bersifat lebih konservatif sebab kehilangan socioemotional wealth berarti kehilangan hubungan keluarga, penurunan status dan kegagalan memenuhi harapan keluarga di perusahaan (Gómez-Mejía dkk., 2007). Perusahaan keluarga memiliki tingkat asimetri informasi yang rendah, tuntutan dari pemangku kepentingan yang sedikit dan kekhawatiran akan mengganggu keuangan perusahaan sehingga perusahaan keluarga menjadi kurang responsif terhadap permintaan pengungkapan dari pemangku kepentingan dan lebih mengutamakan kepentingan keluarga di perusahaan (Gómez-Mejía dkk., 2007; Kim dkk., 2017; Muttakin dan Khan, 2014). Berdasarkan uraian tersebut maka dapat diusulkan hipotesis:

\section{$\mathrm{H}_{1}$ : Kepemilikan keluarga berpengaruh terhadap Carbon Emission Disclosure}

\section{METODE}

Penelitian ini merupakan penelitian kuantitatif dengan pendekatan archival (pengarsipan). Menurut Moers (2007) archival merupakan studi empiris yang menggunakan data arsip sebagai sumber utama dengan menerapkan metode kuantitatif untuk menganalisis data ini. Populasi pada penelitian ini yaitu perusahaan pertambangan yang terdaftar di BEI pada tahun 2016 hingga 2017 yakni sebanyak 82 perusahaan. Fokus utama penelitian ini adalah pada perusahaan keluarga, yaitu sebanyak 46 sampel perusahaan yang dikendalikan oleh keluarga. Proses identifikasi sampel menggunakan teknik sampling jenuh. Dengan teknik ini, data yang diidentifikasi sebagai sampel 
perusahaan keluarga jika pemegang saham utama/pengendali perusahaan dalam populasi adalah sebuah keluarga. Informasi kepemilikan keluarga diperoleh dari laporan tahunan perusahaan pada bagian informasi kepemilikan. Seluruh informasi yang diperlukan dalam penelitian diperoleh dari laporan tahunan perusahaan dari website BEI (www.idx.co.id) dan dari situs resmi perusahaan. Gambar 1 merupakan kerangka konseptual penelitian ini.

Variabel independen pada penelitian ini adalah kepemilikan keluarga. Perusahaan keluarga didefinisikan sebagai perusahaan yang anggota keluarganya aktif di perusahaan sebagai pemilik melalui kepemilikan saham (Block dan Wagner, 2013; Chau dan Gray, 2010; Gallo dan Sveen, 1991). Pengukuran kepemilikan keluarga mengacu pada penelitian Chau dan Gray (2010) yang diukur menggunakan persentase saham yang dimiliki oleh keluarga.

Variabel dependen pada penelitian ini adalah Carbon Emission Disclosure(CDE). Pengukuran variabel mengacu pada penelitian Choi dkk. (2013) yang menggunakan daftar pengungkapan Carbon Disclosure Project (CDP). Daftar tersebut terdiri dari 18 item pengungkapan (Tabel 1) yang terbagi ke dalam 5 kategori yaitu: 1) Perubahan iklim: Resiko dan peluang, 2) Emisi Gas Rumah Kaca, 3) Konsumsi Energi, 4) Pengurangan Gas Rumah Kaca dan Biaya, 5) Akuntabilitas Emisi Karbon. Item yang diungkapan akan diberi nilai 1 dan 0 jika tidak diungkapkan. Daftar tersebut menunjukkan tinggi atau rendah informasi pengungkapan tentang emisi karbon yang dilakukan oleh perusahaan. Total pengungkapan emisi karbon akan diukur menggunakan indeks dengan rumus sebagai berikut:

$$
\mathrm{CED}=\frac{\text { Item yang diungkapkan }}{\text { Total item berdasarkan } C D P} \times 100 \%
$$

Penelitian ini menggunakan dua variabel kontrol yaitu ukuran perusahaan dan usia perusahaan. Ukuran perusahaan diukur menggunakan logaritma natural total aset perusahaan dan usia perusahaan diukur dari lama perusahaan sejak berdiri sampai dengan tahun penelitian.

Untuk menguji hipotesis, penelitian ini menggunakan teknik analisis regresi berganda. Sebelum itu, peneliti juga menyajikan statistik deskriptif untuk menggambarkan informasi dasar perusahaan dan informasi jumlah pengungkapan item emisi karbon dari sampel penelitian. Kemudian, peneliti juga melakukan uji asumsi klasik yang terdiri dari uji normalitas dan uji multikolineritas. Secara sistematis persamaan regresi penelitian dapat dibuat sebagai berikut:

$$
\mathrm{CED}=\alpha+\beta_{1} \mathrm{FOWN}+\beta_{2} \mathrm{SZEC}+\beta_{3} \mathrm{AGEC}+\mathrm{e}
$$

Keterangan:

a

FOWN

SZEC

AGEC

CED

e

: Konstanta

: Kepemilikan keluarga

: Ukuran Perusahaan

: Usia perusahaan

: Luas pengungkapan emisi karbon

: error

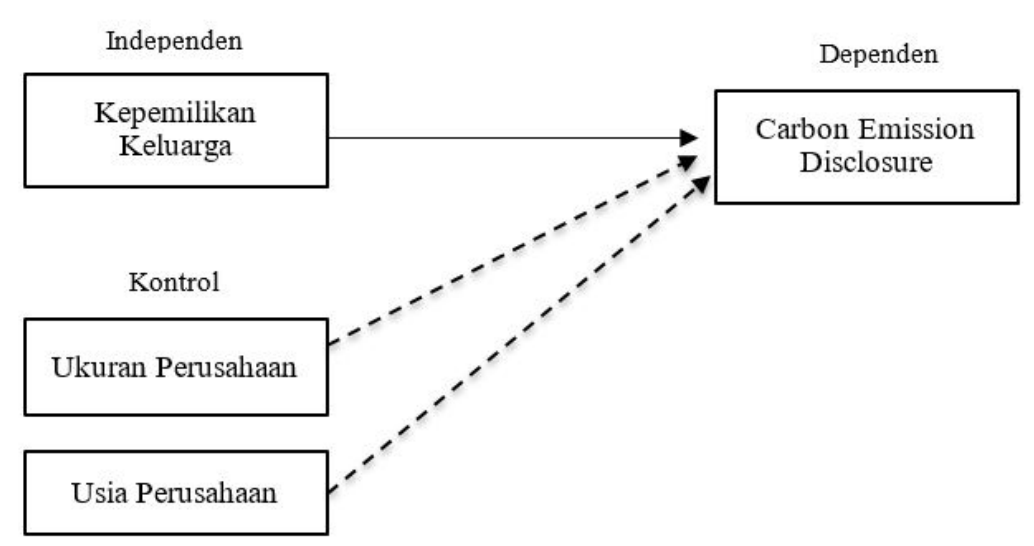

Gambar 1. Kerangka Konseptual Penelitian 
Tabel 1. Daftar Pengungkapan Emisi Karbon

\begin{tabular}{|c|c|c|}
\hline Kategori & Item & Keterangan \\
\hline \multirow[t]{2}{*}{$\begin{array}{l}\text { Perubahan iklim: } \\
\text { Resiko dan Peluang }\end{array}$} & $\mathrm{CC} 1$ & $\begin{array}{l}\text { Penilaian/deskripsi terhadap risiko (peraturan/regulasi baik khusus maupun } \\
\text { umum) yang berkaitan dengan perubahan iklim dan tindakan yang diambil } \\
\text { untuk mengelola risiko tersebut. }\end{array}$ \\
\hline & $\mathrm{CC} 2$ & $\begin{array}{l}\text { Penilaian/deskripsi saat ini (dan masa depan) dari implikasi keuangan, } \\
\text { bisnis dan peluang dari perubahan iklim }\end{array}$ \\
\hline \multirow[t]{7}{*}{$\begin{array}{l}\text { Emisi gas rumah kaca } \\
\text { (GHG/Greehouse Gas) }\end{array}$} & GHG1 & $\begin{array}{l}\text { Deskripsi metodologi yang digunakan untuk menghitung emisi gas rumah } \\
\text { kaca (misal protocol GRK atau ISO). }\end{array}$ \\
\hline & GHG2 & $\begin{array}{l}\text { Keberadaan verifikasi eksternal terhadap penghitungan kuantitas emisi } \\
\text { GRK oleh siapa dan atas dasar apa }\end{array}$ \\
\hline & GHG3 & Total emisi gas rumah kaca (metrik ton CO2-e) yang dihasilkan \\
\hline & GHG4 & Pengungkapan lingkup 1 dan 2, atau 3 emisi GRK langsung \\
\hline & GHG5 & $\begin{array}{l}\text { Pengungkapan emisi GRK berdasarkan asal atau sumbernya (misal: batu } \\
\text { bara, listrik, dll.). }\end{array}$ \\
\hline & GHG6 & Pengungkapan emisi GRK menurut fasilitas atau tingkat segmen \\
\hline & GHG7 & Perbandingan emisi GRK dengan tahun-tahun sebelumnya \\
\hline \multirow{3}{*}{$\begin{array}{l}\text { Konsumsi Energi (EC/ } \\
\text { Energy Consumption) }\end{array}$} & $\mathrm{EC} 1$ & Jumlah energi yang dikonsumsi (misalnya tera-joule atau Peta-joule). \\
\hline & $\mathrm{EC} 2$ & $\begin{array}{l}\text { Penghitungan energi yang digunakan dari sumber daya yang dapat diper- } \\
\text { baharui }\end{array}$ \\
\hline & EC3 & Pengungkapan menurut jenis, fasilitas atau segmen \\
\hline \multirow{4}{*}{$\begin{array}{l}\text { Pengurangan Gas } \\
\text { Rumah Kaca dan Biaya } \\
\text { (RC/Reduction and } \\
\text { Cost })\end{array}$} & $\mathrm{RC} 1$ & Perincian dari rencana atau strategi untuk mengurangi emisi GRK \\
\hline & $\mathrm{RC} 2$ & $\begin{array}{l}\text { Perincian dari tingkat target pengurangan emisi GRK saat ini dan target } \\
\text { pengurangan emisi }\end{array}$ \\
\hline & $\mathrm{RC} 3$ & $\begin{array}{l}\text { Pengurangan emisi dan biaya atau tabungan (costs or savings) yang dicapai } \\
\text { saat ini sebagai akibat dari rencana pengurangan emisi. }\end{array}$ \\
\hline & $\mathrm{RC} 4$ & $\begin{array}{l}\text { Biaya emisi masa depan yang diperhitungkan dalam perencanaan belanja } \\
\text { modal (capital expenditure planning) }\end{array}$ \\
\hline \multirow{2}{*}{$\begin{array}{l}\text { Akuntabilitas Emisi } \\
\text { Karbon (AEC/ } \\
\text { Accountability of } \\
\text { Emission Carbon) }\end{array}$} & $\mathrm{ACC} 1$ & $\begin{array}{l}\text { Indikasi bahwa dewan komite (atau badan eksekutif lainnya) memiliki tang- } \\
\text { gung atas tindakan yang berkaitan dengan perubahan iklim. }\end{array}$ \\
\hline & ACC2 & $\begin{array}{l}\text { Deskripsi mekanisme bahwa dewan (atau badan eksekutif lainnya) me- } \\
\text { ninjau perkembangan perusahaan yang berhubungan dengan perubahan } \\
\text { iklim. }\end{array}$ \\
\hline
\end{tabular}

Sumber : Choi dkk., 2013.

\section{HASIL DAN PEMBAHASAN}

Berdasarkan statistik deskriptif yang disajikan pada Tabel 2, didapat informasi bahwa dari 46 sampel perusahaan, rata-rata kepemilikan keluarga melalui saham di perusahaan sebesar 53,31\%. Nilai terendahnya adalah 3,51\% dan nilai tertingginya adalah 99\%. Pengungkapan emisi karbon perusahaan rata-rata bernilai 0,30 . Nilai terendahnya adalah 0,11 dan nilai tertingginya adalah 0,83 . Ukuran perusahaan yang diukur menggunakan logaritma natural total aset rata-rata bernilai 22,52. Nilai terendahnya adalah 17,31 dan nilai tertingginya adalah 28,63 . Usia perusahaan rata-rata berusia 24 tahun. Usia termudanya adalah 2 tahun dan usia tertuanya adalah 45 tahun.

\section{Statistik Deskriptif}

Berdasarkan data yang disajikan pada Tabel 3, didapat informasi bahwa item pengungkapan terbanyak dari sampel penelitian yaitu informasi akuntabilitas emisi karbon (ACC1 dan ACC2) 
Tabel 2. Statistik Deskriptif

\begin{tabular}{ccccc}
\hline & Minimal & Maksimal & Rata-rata & Standar Deviasi \\
\hline Kepemilikan Keluarga & 3,51 & 99,00 & 53,31 & 25,15 \\
Carbon Emission Disclosure & 0,11 & 0,83 & 0,30 & 0,18 \\
Ukuran Perusahaan & 17,31 & 28,63 & 22,53 & 3,82 \\
Usia Perusahaan & 2,00 & 45,00 & 24,26 & 10,96 \\
N & 46 & & & \\
\hline
\end{tabular}

sebanyak 42 pengungkapan. Hal tersebut menunjukkan bahwa dewan eksekutif perusahaan (direksi dan komisaris) telah memahami akan tanggung jawab perusahaan terhadap perubahan iklim dan aktifitas operasional perusahaan yang dapat berdampak terhadap perubahan iklim. Item pengungkapan terendah dari sampel penelitian yaitu informasi konsumsi energi (EC1 dan EC2) dan informasi biaya pengurangan emisi masa depan perusahaan (RC4) sebanyak 2 pengungkapan. Hal tersebut menunjukkan bahwa perusahaan pertambangan cenderung tidak transparan terhadap sumber daya yang telah digunakan perusahaan dalam aktifitas operasionalnya. Informasi penggunaan sumber daya penting untuk mengetahui apakah perusahaan telah menggunakan sumber daya yang ramah terhadap lingkungan atau tidak. Perusahaan pertambangan juga tidak transparan terhadap biaya masa depan yang akan dikeluarkan oleh perusahaan untuk menangani emisi karbon yang dihasilkan perusahaan.

\section{Uji Asumsi Klasik}

Uji asumsi klasik yang dilakukan dalam penelitian ini adalah uji normalitas dan uji multikolinieritas. Uji normalitas bertujuan untuk menguji apakah dalam metode regresi, variabel yang diuji memiliki distribusi normal (Ghozali, 2011). Uji normalitas dalam penelitian ini menggunakan Kolmogorov-Smirnov. Hasil pengujian menunjukkan bahwa nilai signifikansi sebesar 0,2 (>0,05), maka dapat disimpulkan bahwa data terdistribusi normal. Uji multikolonieritas bertujuan untuk menguji apakah model regresi ditemukan adanya korelasi antar variabel bebas (Ghozali, 2011). Hasil pengujian menunjukkan bahwa nilai VIF semua variabel tidak ada yang bernilai lebih dari 5 (lihat Tabel 4), maka dapat disimpulkan model terbebas dari multikolonieritas.

\section{Uji F}

Berdasarkan hasil pengujian pada Tabel 5, model regresi memiliki nilai signifikansi sebesar $\mathrm{F}<$ 0,05. Berarti secara simultan variabel kepemilikan keluarga, ukuran perusahaan dan usia perusahaan berpengaruh terhadap pengungkapan emisi karbon.

\section{Koefisien Determinasi}

Berdasarkan hasil pengujian pada Tabel 6 , model regresi sebelum memasukkan variabel kontrol memiliki nilai adjusted $R$ Square sebesar $28,9 \%$. Hal tersebut menunjukkan bahwa variabel kepemilikan keluarga dapat menjelaskan variasi pengungkapan emisi karbon sebesar nilai adjusted $R$ Square. Model regresi setelah memasukkan variabel kontrol memiliki nilai adjusted $R$ Square sebesar 31,8\%. Hal ini menunjukkan bahwa variabel kepemilikan keluarga, ukuran perusahaam dan usia perusahaan dapat menjelaskan variasi pengungkapan emisi karbon sebesar nilai adjusted $R$ Square. Perbandingan nilai koefisien diterminasi sebelum dan sesudah memasukkan variabel kontrol menunjukkan adanya peningkatan nilai adjusted $R$ Square. Hal tersebut menunjukan bahwa variabel kontrol yang digunakan dapat memperbaiki model penelitian untuk menjelaskan variasi pengungakapan emisi karbon.

\section{Uji Koefisien Regresi}

Berdasarkan persamaan regresi di Tabel 7, hasil persamaan dapat disajikan sebagai berikut:

$$
\mathrm{CED}=0,684-(0,004)-(0,011)+0,002+\mathrm{e}
$$

Uji koefesien regresi yang disajikan pada Tabel 7 menunjukkan bahwa nilai signifikansi variabel kepemilikan keluarga sebesar $\mathrm{p}<0,05$ maka dapat disimpulkan bahwa kepemilikan keluarga berpengaruh negatif dan signifikan terhadap pengungkapan emisi karbon, sehingga hipotesis yang menyatakan bahwa kepemilikan keluarga berpengaruh terhadap pengungkapan emsisi karbon tidak dapat ditolak. Hasil tersebut bertentangan dengan penelitian Kalu dkk. (2016) yang menemukan bahwa struktur kepemilikan baik terkonsentrasi maupun tersebar tidak berpengaruh signifikan terhadap pengungkapan emisi karbon. Perbedaan hasil penelitian dengan Kalu dkk. (2016) dapat 
Tabel 3. Indikator Pengungkapan Emisi Karbon

\begin{tabular}{|c|c|c|}
\hline Item & Keterangan & Jumlah Pengungkapan \\
\hline $\mathrm{CC} 1$ & $\begin{array}{l}\text { Penilaian/deskripsi terhadap risiko (peraturan/regulasi baik khusus } \\
\text { maupun umum) yang berkaitan dengan perubahan iklim dan tinda- } \\
\text { kan yang diambil untuk mengelola risiko tersebut. }\end{array}$ & 40 \\
\hline $\mathrm{CC} 2$ & $\begin{array}{l}\text { Penilaian/deskripsi saat ini (dan masa depan) dari implikasi keuan- } \\
\text { gan, bisnis dan peluang dari perubahan iklim }\end{array}$ & 38 \\
\hline GHG1 & $\begin{array}{l}\text { Deskripsi metodologi yang digunakan untuk menghitung emisi gas } \\
\text { rumah kaca (misal protocol GRK atau ISO). }\end{array}$ & 20 \\
\hline GHG2 & $\begin{array}{l}\text { Keberadaan verifikasi eksternal terhadap penghitungan kuantitas } \\
\text { emisi GRK oleh siapa dan atas dasar apa }\end{array}$ & 4 \\
\hline GHG3 & Total emisi gas rumah kaca (metrik ton CO2-e) yang dihasilkan & 4 \\
\hline GHG4 & Pengungkapan lingkup 1 dan 2, atau 3 emisi GRK langsung & 4 \\
\hline GHG5 & $\begin{array}{l}\text { Pengungkapan emisi GRK berdasarkan asal atau sumbernya (misal: } \\
\text { batu bara, listrik, dll.). }\end{array}$ & 6 \\
\hline GHG6 & Pengungkapan emisi GRK menurut fasilitas atau tingkat segmen & 6 \\
\hline GHG7 & Perbandingan emisi GRK dengan tahun-tahun sebelumnya & 4 \\
\hline $\mathrm{EC} 1$ & Jumlah energi yang dikonsumsi (misalnya tera-joule atau Peta-joule). & 2 \\
\hline $\mathrm{EC} 2$ & $\begin{array}{l}\text { Penghitungan energi yang digunakan dari sumber daya yang dapat } \\
\text { diperbaharui }\end{array}$ & 2 \\
\hline EC3 & Pengungkapan menurut jenis, fasilitas atau segmen & 2 \\
\hline $\mathrm{RC} 1$ & Perincian dari rencana atau strategi untuk mengurangi emisi GRK & 12 \\
\hline $\mathrm{RC} 2$ & $\begin{array}{l}\text { Perincian dari tingkat target pengurangan emisi GRK saat ini dan } \\
\text { target pengurangan emisi }\end{array}$ & 10 \\
\hline $\mathrm{RC} 3$ & $\begin{array}{l}\text { Pengurangan emisi dan biaya atau tabungan (costs or savings) yang } \\
\text { dicapai saat ini sebagai akibat dari rencana pengurangan emisi. }\end{array}$ & 6 \\
\hline $\mathrm{RC} 4$ & $\begin{array}{l}\text { Biaya emisi masa depan yang diperhitungkan dalam perencanaan } \\
\text { belanja modal (capital expenditure planning) }\end{array}$ & 2 \\
\hline $\mathrm{ACC} 1$ & $\begin{array}{l}\text { Indikasi bahwa dewan komite (atau badan eksekutif lainnya) memi- } \\
\text { liki tanggung atas tindakan yang berkaitan dengan perubahan iklim. }\end{array}$ & 42 \\
\hline $\mathrm{ACC} 2$ & $\begin{array}{l}\text { Deskripsi mekanisme bahwa dewan (atau badan eksekutif lainnya) } \\
\text { meninjau perkembangan perusahaan yang berhubungan dengan } \\
\text { perubahan iklim. }\end{array}$ & 42 \\
\hline
\end{tabular}

Tabel 4. Uji Multikolinieritas

\begin{tabular}{ccc}
\hline Variabel & Statistik Koleniaritas & VIF \\
\hline Kepemilikikan Keluarga & Toleransi & 1,023 \\
Ukuran Perusahaan & 0,977 & 1,057 \\
Usia Perusahaan & 0,946 & 1,061 \\
\hline
\end{tabular}

Tabel 5. Uji F

\begin{tabular}{cccc}
\hline Uji Signifikansi $\mathbf{F}$ & $\boldsymbol{\alpha}=\mathbf{5 \%}$ & Hasil & Kesimpulan \\
\hline 0,000 & 0,05 & Sig. $\mathrm{f}<0,05$ & Berpengaruh secara simultan \\
\hline
\end{tabular}


Tabel 6. Koefisien Determinasi Sebelum dan Sesudah Memasukkan Variabel Kontrol

\begin{tabular}{ccrrr}
\hline & R & R Square & Adjusted R Square & Std. Error of the Estimate \\
\hline Sebelum & 0,552 & 0,304 & 0,289 & 0,15060 \\
Sesudah & 0,603 & 0,364 & 0,318 & 0,14745 \\
\hline
\end{tabular}

Tabel 7. Uji Koefisien Regresi

\begin{tabular}{llcrcrr}
\hline \multicolumn{1}{c}{ Model B } & \multicolumn{2}{c}{$\begin{array}{c}\text { Unstandardized } \\
\text { Coefficients }\end{array}$} & \multicolumn{2}{c}{$\begin{array}{c}\text { Standardized } \\
\text { Coefficients }\end{array}$} & t & Sig. \\
& Std. Error & Beta & & & 4.931 & .000 \\
\hline \multirow{2}{*}{1} & (Constant) & .684 & .139 & -.518 & -4.156 & .000 \\
& Kepemilikan Keluarga & -.004 & .001 & -.233 & -1.842 & .073 \\
& Ukuran Perusahaan & -.011 & .006 & .139 & 1.095 & .280 \\
\hline
\end{tabular}

terjadi karena peneliti mengkombinasikan tiga struktur kepemilikan perusahaan yaitu pemegang saham mayoritas, minoritas, dan tiga pemegang saham terbesar. Kombinasi tersebut dilakukan berdasarkan definisi perusahaan keluarga yang menyatakan bahwa suatu perusahaan dapat disebut sebagai perusahaan keluarga jika terdapat anggota keluarga aktif di perusahaan sebagai pemilik melalui kepemilikan saham (Block dan Wagner, 2013; Chau dan Gray, 2010; Gallo dan Sveen, 1991). Berdasarkan definisi tersebut perusahaan keluarga tidak hanya melihat keluarga sebagai pemegang saham mayoritas saja. Kombinasi tersebut memungkinkan terjadi bias prinsip antar pemegang saham yang dapat mempengaruhi kebijakan perusahaan terkait motivasi kebijakan pengungkapan informasi sukarela dari pemilik perusahaan, karena Oh dkk. (2011) berargumen bahwa pemegang saham yang berbeda memiliki motivasi yang berbeda terhadap pengungkapan informasi non keuangan. Namun, hasil tersebut sejalan dengan penelitian Gonzalez-Gonzalez dan Zamora-Ramírez (2016) bahwa perusahaan yang memiliki struktur kepemilikan yang terkonsentrasi memiliki pengaruh yang signifikan dan negatif terhadap pengungkapan. Perusahaan keluarga merupakan perusahaan yang secara umum merupakan jenis kepemilikan yang terkonsentrasi dimana hanya terdapat sedikit pemegang saham yang memiliki proporsi kepemilikan yang besar yang juga merupakan pengendali perusahaan. Namun, pada kondisi tertentu dapat ditemui perusahaan yang dimiliki oleh keluarga dengan kepemilikan saham yang kecil dan tersebar namun pengendali perusahaan tetap dipegang oleh keluarga.

Pada perusahaan yang dimiliki oleh keluarga, pemangku kepentingan utama (pemegang saham, manajemen perusahaan) cenderung berada di pihak keluarga itu sendiri. Hal ini sesuai dengan teori sosioemotional wealth (Gómez-Mejía dkk. 2007) yang mengatakan bahwa perusahaan yang dimiliki oleh keluarga cenderung akan mempertahan pengaruhnya di perusahaan. Salah satu cara yang dilakukan yaitu dengan memiliki saham perusahaan atau menempatkan orang kepercayaan atau pemegang saham utama itu sendiri pada jajaran manajerial (Husnan, 2001). Argumentasi tersebut didukung statistik deskriptif penelitian ini, yaitu perusahaan pertambangan di Indonesia mempunyai rata-rata kepemilikan saham oleh keluarga di atas 50\%, sehingga dapat dikatakan bahwa keluarga mempunyai kendali atas perusahaan. Sesuai dengan Peraturan Bank Indonesia Nomor 12/23/ PBI/2010 Tahun 2010 tentang Uji Kemampuan dan Kepatutan (Fit And Proper Test) mendefinisikan pemegang saham pengendali adalah badan hukum, orang perseorangan dan/atau kelompok usaha yang memiliki saham perusahaan atau Bank sebesar 25\% atau lebih dari jumlah saham yang dikeluarkan dan mempunyai hak suara; atau memiliki saham perusahaan atau Bank kurang dari $25 \%$ dari jumlah saham yang dikeluarkan dan mempunyai hak suara namun dapat melakukan pengendalian perusahaan atau Bank, baik secara langsung maupun tidak langsung (pasal 1). Kondisi tersebut membuat keluarga sebagai pengendali perusahaan memandang tindakan menyamakan prinsip agar diterima oleh masyarakat dan pemangku kepentingan lain menjadi tidak terlalu relevan, karena pemangku kepentingan utama (misalnya pemegang saham) merupakan keluarga sendiri. Kemudian, kondisi tersebut juga memberikan kesempatan kepada keluarga sebagai pengendali untuk mengakses langsung informasi keuangan maaupun informasi non keuangan perusahaan (Chau dan Gray, 2010). Kesempatan tersebut membuat keluarga tidak membutuhkan pengungkapan yang komprehensif pada topik emisi karbon.

Hasil penelitian ini menunjukkan bahwa semakin besar kepemilikan saham oleh keluarga di perusahaan, maka semakin besar pengendalian keluarga di perusahaan. Hal tersebut akan mempengaruhi 
kebijakan perusahaan yang berkaitan dengan pengungkapan. Pada perusahaan pertambangan di Indonesia, hasil penelitian menunjukkan bahwa ketika keluarga adalah pengendali perusahaan melalui kepemilikan saham, maka informasi mengenai emisi karbon cenderung tidak diungkapkan secara komprehensif. Berdasarkan data pada Tabel 3, perusahaan pertambangan yang dimiliki oleh keluarga cenderung tidak transparan atas informasi aktivitas operasional dan dampak emisi karbon yang dihasilkan. Hanya terdapat sedikit item pengungkapan yang diungkapan secara mayoritas oleh perusahan pertambangan yang dimiliki oleh keluarga. Hal tersebut terjadi karena pemilik perusahaan adalah pihak yang dapat terlibat langsung dalam aktivitas perusahaan. Keterlibatan pemilik menjadikan informasi-informasi non keuangan mudah didapatkan sehingga pengungkapan yang komprehensif sebagai mekanisme kontrol menjadi tidak dibutuhkan (Ho dan Wong, 2001).

Hasil penelitian ini sejalan dengan teori sosioemotional wealthyang mengatakan bahwa pengungkapan informasi sukarela pada perusahaan keluarga akan berada pada tingkat yang rendah karena perusahaan keluarga memiliki tingkat asimetri informasi yang rendah, tuntutan dari pemangku kepentingan yang sedikit dan kekhawatiran akan mengganggu keuangan perusahaan sehingga perusahaan keluarga menjadi kurang responsif terhadap permintaan pengungkapan dari pemangku kepentingan dan lebih mengutamakan kepentingan keluarga di perusahaan (Gómez-Mejía dkk., 2007; Kim dkk., 2017; Muttakin dan Khan, 2014). Goodland (2012) menyatakan bahwa perusahaan pertambangan sering menghancurkan lingkungan masyarakat serta ekosistem dan hampir terjadi di seluruh dunia. Bagi perusahaan keluarga, pelaksanaan dan pengungkapan emisi karbon yang komprehensif berarti akan meningkatkan biaya yang harus dikeluarkan. Gómez-Mejía dkk. (2007) berargumen bahwa perusahaan keluarga akan berusaha menjaga perusahaan dari risiko kinerja keuangan jangka panjang. Upaya yang dilakukan oleh perusahaan yaitu mengurangi pelaksanaan dan pengungkapan informasi sukarela walaupun terjadi peningkatan permintaan dari masyarakat dan pemangku kepentingan lain. Hal tersebut sejalan dengan argumen yang menyatakan bahwa ketika keluarga sebagai pemegang saham pengendali, kebutuhan akan pengungkapan yang komprehensif akan rendah, sehingga pemilik kurang responsif terhadap harapan masyarakat dan pemangku kepentingan lain sehingga tingkat pelaporan bersifat negatif (Kim dkk., 2017).

Peneliti juga berargumen bahwa perusahaan pertambangan yang dimiliki oleh keluarga cenderung tidak mengungkapkan informasi emisi karbon secara komprehensif karena belum adanya regulasi dari pemerintah yang mewajibkan pengungkapan tersebut. Regulasi bisa menjadi standar yang dapat digunakan oleh perusahaan-perusahaan mengenai hal-hal material yang harus diungkapkan. Tidak adanya regulasi berarti hal-hal material mungkin tidak akan diperhatikan, padahal perusahaan pertambangan adalah salah satu industri yang banyak menggunakan bahan bakar fosil yang bisa meningkatkan efek gas rumah kaca. Perusahaan keluarga juga memandang aktivitas yang berhubungan dengan kegiatan sosial dan lingkungan berserta pelaporannya merupakan sumber biaya dan tidak dilihat sebagai peluang, sehingga perusahaan lebih tertarik pada profitabilitas dan kinerja keuangan daripada aspek sosial dan lingkungan (Déniz dan Suárez, 2005).

\section{SIMPULAN}

Indonesia telah berkomitmen untuk ikut serta pada program pengurangan gas rumah kaca dengan mengeluarkan Undang-Undang No. 17 tahun 2004. Komitmen tersebut tidak serta-merta mendorong kepedulian perusahaan untuk mengungkapkan informasi terkait emisi karbon secara komprehensif. Hasil penelitian ini menunjukkan bahwa perusahaan tidak mengungkapkan informasi dengan cukup material agar dapat dilihat dengan mudah jumlah konsumsi dan emisi yang dihasilkan oleh perusahaan tersebut.

Berdasarkan hasil penelitian ini dapat diambil kesimpulan bahwa kepemilikan keluarga pada perusahaan pertambangan yang terdaftar di BEI periode 2016 hingga 2017 berpengaruh negatif terhadap pengungkapan emisi karbon. Informasi mengenai emisi karbon yang dihasilkan perusahaan pertambangan tidak komprehensif. Kebaharuan penelitian ini yaitu mengisi gap dari penelitian sebelumnya yang belum banyak membahas faktor struktur kepemilikan terutama kepemilikan keluarga sebagai variabel yang dapat memengaruhi motivasi perusahaan untuk mengungkapkan emisi karbon.

Keterbatasan penelitian ini yaitu pada proses identifikasi apakah sebuah perusahaan dapat diklasifikasikan sebagai perusahaan keluarga atau tidak, karena tidak semua laporan tahunan menyajikan informasi kepemilikan keluarga dengan jelas, sehingga dimungkinkan terdapat perusahaan yang sebenarnya dimiliki oleh keluarga tetapi tidak terindentifikasi karena keterbatasan informasi. Penelitian selanjutnya dapat menguji variabel struktur kepemilikan yang lain seperti kepemilikan pemerintah, kepemilikan manajerial, kepemilikan asing, dan lain-lain karena kepemilikan yang berbeda memungkinkan memiliki motivasi yang berbeda terhadap pengungkapan. Penelitian ini memberikan implikasi bahwa perusahaan pertambangan keluarga cenderung tidak mengungkapkan informasi mengenai emisi karbon yang dihasilkan perusahaan secara komprehensif, sehingga diperlukan kebijakan pemerintah untuk meningkatkan kepatuhan pengungkapan. 


\section{DAFTAR RUJUKAN}

Ben-Amar, W., Chang, M., \& McIlkenny, P. (2017). Board Gender Diversity and Corporate Response to Sustainability Initiatives: Evidence from the Carbon Disclosure Project. Journal of Business Ethics, 142(2), 369-383.

Block, \& Wagner, M. (2013). The Effect of Family Ownership on Different Dimensions of Corporate Social Responsibility: Evidence from Large US Firms. Business Strategy and the Environment, 23, 475-492.

Chau, G., \& Gray, S. J. (2010). Family Ownership, Board Independence and Voluntary Disclosure: Evidence from Hong Kong. Journal of International Accounting; Auditing and Taxation, 19(2), 93-109.

Choi, B. B., Lee, D., \& Psaros, J. (2013). An analysis of Australian Company Carbon Emission Disclosures. Pacific Accounting Review, 25(1), 58-79.

Déniz, M. d. 1. C. D., \& Suárez, M. K. C. (2005). Corporate Social Responsibility and Family Business in Spain. Journal of Business Ethics, 56(1), 27-41.

Gallo, M. A., \& Sveen, J. (1991). Internationalizing the Family Business: Facilitating and Restraining Factors. Family Business Review, 4(2), 181-190.

Ghozali, I. (2011). Aplikasi Analisis Multivariate dengan Program IBM SPSS 19 (pp. 160). Semarang: Badan Penerbit Universitas Diponegoro.

Gómez-Mejía, Haynes, K. T., Núñez-Nickel, M., Jacobson, K. J., \& Moyano-Fuentes, J. (2007). Socioemotional Wealth and Business Risks in Family-Controlled Firms: Evidence from Spanish Olive Oil Mills. Administrative Science Quarterly, 52(1), 106-137.

Gonzalez-Gonzalez, J. M., \& Zamora-Ramírez, C. (2016). Voluntary Carbon Disclosure by Spanish Companies: An Empirical Analysis. International Journal of Climate Change Strategies and Management, 8(1), 57-79.

Goodland, R. (2012). Responsible Mining: The Key to Profitable Resource Development. Sustainability, 4(9), 2099-2126.

Ho, S. S., \& Wong, K. S. (2001). A study of the Relationship Between Corporate Governance Structures and the Extent of Voluntary Disclosure. Journal of International Accounting, Auditing and Taxation, 10(2), 139-156.

Husnan, S. (2001). Corporate Governance \& Finance in East Asia: A Study of Indonesia, Republic of Korea, Malaysia, Philippines and Thailand: Asian Development Bank.

Irwhantoko, I., \& Basuki, B. (2016). Carbon Emission Disclosure: Studi pada Perusahaan Manufaktur Indonesia. Jurnal Akuntansi dan Keuangan, 18(2), 92-104.

Kalu, J. U., Buang, A., \& Aliagha, G. U. (2016). Determinants of Voluntary Carbon Disclosure in the Corporate Real Estate Sector of Malaysia. Journal of environmental management, 182, 519-524.

Kellermanns, F. W., Eddleston, K. A., \& Zellweger, T. M. (2012). Extending the Socioemotional Wealth Perspective: A Look at the Dark Side. Entrepreneurship Theory and Practice, 36(6), 1175-1182.

Kılıç, M., \& Kuzey, C. (2019). The Effect of Corporate Governance on Carbon Emission Disclosures: Evidence from Turkey. International Journal of Climate Change Strategies and Management, 11(1), 35-53.

Kim, J., Fairclough, S., \& Dibrell, C. (2017). Attention, Action, and Greenwash in Family-Fnfluenced Firms? Evidence from Polluting Industries. Organization \& Environment, 30(4), 304-323.

Moers, F. (2007). Doing Archival Research in Management Accounting. Handbooks of management accounting research, 1, 399-413.

Muttakin, M. B., \& Khan, A. (2014). Determinants of Corporate Social Disclosure: Empirical Evidence from Bangladesh. Advances in accounting, 30(1), 168-175.

Nasih, M., Harymawan, I., Paramitasari, Y. I., \& Handayani, A. (2019). Carbon Emissions, Firm Size, and Corporate Governance Structure: Evidence from the Mining and Agricultural Industries in Indonesia. Sustainability, 11(9), 2483. 
Oh, W. Y., Chang, Y. K., \& Martynov, A. (2011). The Effect of Ownership Structure on Corporate Social Responsibility: Empirical Evidence from Korea. Journal Business Ethic, 104, 283-297. doi: 10.1007/s10551-011-0912-z

PWC. (2014). Survey Bisnis Keluarga. 
Halaman ini sengaja dibiarkan kosong. 